\title{
INTRODUCTORY NOTE \\ ON THE ONE AND MANY: THE APORIAS \\ OF OUR RESTLESSNESS
}

\author{
Zara Pinto-Coelho and Silvana Mota-Ribeiro
}

The present volume of the journal Comunicação e Sociedade (Communication and Society) is dedicated to the theme of Gender and heterosexuality: discourses and images in advertising and the media. It stems from a research project with an identical naming, within the scope of which the editors of this volume have explored the themes in the context of women's magazines and general print media news discourse over the last 5 years. This is the first volume dedicated to this theme on the research strand of "Language and Social Interaction" and the CECS' collection. It was encouraged by the desired contribution to questioning the continuing (re) production of the link between gender and heterosexuality that establishes a causal relationship between sex, gender and desire (Butler, 1990). This task is ever more urgent than the isms that are articulated about these issues are unnecessary, obsolete and regressive. Given the emphasis that we place on discourse and the image, it is relevant to question how gender and sexuality can be intertwined with this type of communicative events and social practices.

Although we agree with Rubin's claim (Rubin, [1984]1999) that sex and gender are not the same thing, and that analytically sexuality and gender should be distinguished, we also think, like many other feminist theorists, including Rubin (who had claimed this same position in her seminal 1975 essay (Rubin, 1975)) that sex and gender are separated systems which are interwoven at several points. They have a particular kind of mutual dependence, which no study of either can overlook (Cameron \& Kulick, 2003; Bucholtz \& Hall, 2004).

It is by now a familiar finding - reported by several researchers working in Anglo-American cultures - that the discursive construction of heterosexuality is often bound to the discursive construction of femininity and of masculinity (Hollway, 1984; Rich, 1999; Sunderland, 2004). In this discursive chaining between gender and heterosexuality, heterosexual identities are represented as natural, the product of the anatomically sexed body (whether female or male), while gender identities are seen as signifying the meanings attributed to the sexed body (whether feminine or masculine). This distinction between sex and gender entails the understanding that male bodies are the basis of masculinity and female bodies the basis of femininity and the construction of an established binary heterosexual order upon which normative gender is built. In the domain of sexuality, this is visible in the naturalness of the two-sex idea, and in the notion that the two must be inherently contrasting. This contrast is read in most cultures, according to Cameron and Kulick (2003), as complementary (i.e., matching what the 'opposite sex' is not), and is rendered desirable, awarding heterosexuality with validity and authority as the only natural and normal sexuality. The coherence of the articulation between 'gender differences discourse' (Hollway, 1984) and the dominant heterosexuality discourse, where the binary structure of gender finds its complement in opposite-sex attraction, is insured by the dominant ideology of gender. According to this ideology: 
'real men axiomatically desire women, and true women want men to desire them. Hence, if you are not heterosexual you cannot be a real man or a true woman; and if you are not a real man or woman then you cannot be heterosexual' (Cameron \& Kulick, 2003: 6).

Since discourse about heterosexuality, or more generally about sex, sexuality and gender is not static and homogenous, 'the rules through which we organise our understanding of sex and gender are not always and everywhere identical' (Cameron \& Kulick, 2003: 43). As far as gender is concerned, the historian Joan Wallach Scott (1999) points to these contradictions in culturally available symbols in the Western Christian tradition that evoke multiple (and often contradictory) representations Eve and Mary as symbols of Woman, for example, but also myths of light and dark, purification and pollution, innocence and corruption (Tseëlon, 1995; Ussher, 1997; Weitz, 1998). In this vein, Hollway (1984) sees heterosexuality as constructed by the way in which 'at a specific moment several coexisting and potentially contradictory discourses concerning sexuality make available different positions and different powers for men and women' (1984: 230). This diversity is one of the reasons why power effects of discourses should be analysable in the context of orders of discourse (Fairclough, 1992) and of a larger system of sometimes opposing, contradictory, competing, contesting or merely different discourses (Kress, 1989). However, not all discourses have the same power. Discourses are fluid. They do not have an objective beginning and a clearly defined end (Wodak, 1997: 6). They are fluid and opportunistic, and concurrently draw upon existing discourses about an issue whilst utilising, interacting with, and being mediated by other discourses. It was precisely to better understand this complexity about gender and heterosexuality in the media and advertising that we launched our project and edited this volume of the journal.

This volume includes a collection of texts that discuss issues related to discourses, representations and stereotypes of femininity, masculinity and heterosexuality in the media (TV, cinema, journalism) and advertising (women and men magazines), and show the complexity and instability that permeate them in different contexts. Only three articles are inscribed in a different scope from this central nucleus (part III). José Aguaded, Ángel Hernando-Gómez and Amor Pérez focus on the new audio-visual landscape, which according to them reinforces a new imagedbased culture, in which appearance, spectacle and the mosaic predominate. A new context for education is urgently required, and media education is the key giving citizens the audio-visual skills they need to use media in a rational, intelligent and entertaining way. Manuel Barbosa sustains that the media realize and shape, to a great extent, the public perception and the acceptance / rejection of multiculturalism and interculturalism. The author claims that this "so-called 'fourth power'" can play a relevant role in the construction of a culturally inclusive citizenship and that this implies the need for its regulation and supervision. In his discussion about telereality and televiolence that characterize TV in a hyper-globalized world, Philippe Joron writes about the decomposition of conventional media frameworks, the "defenestration", and the sacralisation of everyday life in the media.

The articles gathered in parts I and II cover various areas within this volume thematic. The first part starts with Daniella de Menezes' article, which aims at identifying the moral values evoked in the construction of the woman's images in advertisements published in informative female and male-targeted magazines, using a 
linguistic analysis, inspired by several French authors. Her analysis of images is not limited by one sole possible reading. On the contrary, she explores various and different effects, contradictions and discourses beneath the superficiality of words and in the interplay between images and text. The main objective is to facilitate teachers' and other professionals' linked to the akin areas methodological reflections concerning the reading of advertising texts as well as their reflections on the ethical character that involves woman as a main appeal in ads. De subsequent topic is cinema. Emanuella de Moraes and Marinyze de Oliveira guide us into the life and the construction of images of the women in the film Love for Sale, offering a discussion of the multiplicity of female identities at play. They do so by exploring the behaviour of the female characters, framing them within the main themes of heterosexuality: romantic love, sexuality, motherhood and liberty. Marcelo Santos and Maria Ribeiro lead us into a case of applied psychoanalysis. They conduct an analysis of the covers of the magazines Men's Health and G Magazine in the light of the psycho-analytical theory informed by a Freudian-Lacanian orientation, to argue that this is, mainly, a theory of language. Based on abstract logical-formal elements that structure the unconscious as discourse, they conclude that there are considerable differences between the two magazines, despite their apparent similarities. The ways the Brazilian media represent aging is discussed by Maria Luisa Mendonça in the scope of the processes of female identity and subjectivity construction, illustrated by using a mini-series on this theme as an example. She invests herself politically, by stating that her research on the discourses of aging aims to break the stereotypes, preconceptions and hierarchies. In Raphael Bispo's work, gender is problematized within the field of artistic careers in the Brazilian emergent cultural industry. By combining a symbolic interactionist perspective with more contemporary approaches to gender and sexuality, the author explores the life histories of women stage dancers on $\mathrm{TV}$, from the $60 \mathrm{~s}$ to the $80 \mathrm{~s}$, who participated in mass media production and the consolidation of the entertainment industry. The presence of women in this space, while Brazil was under dictatorship, has created strong symbolic meanings that, in many cases, associated TV dancing with prostitution. Raphael analyses the social contexts and gender relations linked to those negative meanings and accusations, in order to understand how these "chacretes" walked a thin line, within the limits of those judgments. They used parody about heterosexual women, by exaggeration o socially expected femininity, in order to gain visibility on TV.

Moving on to the field of advertising, Sandra Tuna and Elsa Freitas focus on fragrances as symbols of individuality and sexual orientation, aiming to account for the themes, forms of representation and motives featured in fragrance advertisements. The research conducted by the authors, visually illustrated, concludes that the forms of representation are stereotyped in terms of the participants' gender, suggesting, notwithstanding, the existence of less conservative features. Also within the field of advertisements, Simone Freitas explores a classical area within gender advertising research. Her exploratory study is based upon her PhD dissertation about male stereotypes in TV advertisements in Brazil and Portugal, using a content analysis methodology. In the field of media in general, Sonia Farber produces a reflection about the ageing process (of the "elder" or "old" age human being) and the representations of death, offering equally an overview of how aging has been understood over different eras and societies. By concluding that currently the media reinforce and establish contradictory concepts of old age, she thus contributes to a 
better understanding of a complex problem. Back to advertising, it is the male body which is focused on again in Soraya Januário and António Cascais' article. The authors explore the use of that body as an object of desire and self-representation, in order to sell products and consumption habits, and emphasize that not a long time ago it was the eroticization of the female body that played a crucial role to attract male consumers. This article identifies forms of representing masculinities linked to an appropriation of bodily image, in Calvin Klein, Dolce o Gabanna and Jean Paul Gaultier campaigns, published in men's magazines: Men's Health, FHM and QG, through a content a semiological analysis. A new reading of the male body is offered, as the advertising discourse show important reconfigurations in male identity, as well as variety, new patterns and norm deviation.

Part II opens with Cláudia Álvares perspective about discourses of exoticism in women's magazines. Informed by CDA (Wodak) perspective, the author aims at understanding the way in which gender discourse articulated in women's magazines related to consumption practices based on exoticism intertwines with a pots-feminist discourse. She does so through a linguistic analysis of articles published in Máxima and Cosmo magazines, in order to understand the discursive strategies used in the construction of a consensual normative female identity through stereotypes of European alterities. Journalism as a profession is the focus of Maria João Silveirinha. In a response to a James Carey challenge, about the history of journalism, the author problematizes the historical relation of women with journalism as a profession. This is done within the scope of a transnational context. The study focuses on the sex of the news, the role and importance of women in the history of journalism, in order not only to document facts, but also capture the lived meanings of the profession by women journalists. In "Gender, war and body politics: a critical multimodal analysis of metaphor in advertising", Michel Lazar explores how beauty is metaphorically conceptualized in advertising as war. Drawing upon a corpus of print beauty advertisements, her critical multimodal approach shows how the war metaphor is expressed through a combination of language, colour, and visual images. Framed by a feminist discourse analytic perspective, explores the contradictory elements in the construction of a postfeminist feminine identity in the advertisements, and the implications of using a military metaphor to conceptualize empowerment for women. Also in the thematic scope of advertising, in this case, women's magazines, Zara Pinto-Coelho and Silvana Mota-Ribeiro aim at identifying the visual strategies by which heterosexist discourses are (re)produced in ads published in women's magazines, in ways which may be transformative as well as reproductive of the western hetero-gendered hegemonic order. The visual workings are approached from a social semiotic point of view, and analysed according to Kress and van Leeuwen's system of analysis (1996).

The reviews that closes this journal issue cover topics related to it. Ana Brandão presents a book by Rodger Streitmatter, (1995) Unspeakable: The Rise of the Gay and Lesbian Press in America, and Zara Pinto-Coelho presents a work of Mary Talbot (2007) Media Discourse. Representation and Interaction. 


\section{REFERENCES}

Bucholtz, M. \& Hall, K. (2004) 'Theorizing Identity in Language and Sexuality Research', Language in Society, 33(4): 501-547.

Butler, Judith (1990) Gender Trouble: Feminism and the Subversion of Identity, London: Routledge.

Cameron, D. \& Kulick, D. (2003) Language and Sexuality, Cambridge: Cambridge University Press.

Fairclough, N. (1992) Discourse and Social Change, Cambridge: Polity Press.

Hollway, W. (1984) 'Gender Difference and the Production of Subjectivity' in Henriques, J., Hollway, W., Urwin, C., Venn, C. \& Walkerdine, V. (eds.), Changing the Subject: Psychology, Social Regulation and Subjectivity, London: Methuen, pp. 227-263.

Kress, G. (1989) Linguistic Processes in Sociocultural Practice, Oxford: Deakin University, Oxford University Press.

Rich, A. (1999) 'Compulsory Heterosexuality and Lesbian Existence' in Aggleton, P. \& Parker, R. (eds.), Culture, Society and Sexuality: A Reader, London: UCL Press, pp. 199-225.

Rubin, G. ([1984] 1999) 'Thinking Sex: Notes for a Radical Theory of the Politics of Sexuality' in Aggleton, P. \& Parker, R. (eds.), Culture, Society and Sexuality: A Reader, London: UCL Press, pp. 143-179.

Rubin, G. (1975) 'The Traffic in Women: Notes on the 'Political Economy' of Sex' in R. Reiter (ed.), Toward an Anthropology of Women, New York: Monthly Review Press.

Scott, J. ([1988] 1999) Gender and the Politics of History, New York: Columbia University Press, revised edition.

Sunderland, J. (2004) Gendered Discourses, New lorque: Palgrave Macmillan.

Tseëlon, E. (1995) The Masque of Femininity, London: Sage.

Ussher, J. (1997) Fantasies of Femininity: Reframing the Boundaries of Sex, London: Penguin.

Weitz, R. (1998) 'A History of Women's Bodies' in R. Weitz (ed.), The Politics of Women's Bodies Sexuality, Appearance, and Behavior, Oxford: Oxford University Press, pp. 3-11.

Wodak, R. (1997) 'Introduction: Some Important Issues in the Research of Gender and Discourse' inn R. Wodak (ed.), Gender and Discourse, London: Sage. 